\title{
Fontes de lipídio e monensina sódica na fermentação, cinética e degradabilidade ruminal de bovinos
}

\author{
Amaury Camilo Valinote ${ }^{(1)}$, José Carlos Machado Nogueira Filho(1), Paulo Roberto Leme ${ }^{(1)}$, \\ Saulo da Luz e Silva ${ }^{(1)}$ e José Aparecido Cunha ${ }^{(1)}$
}

(1)Universidade de São Paulo, Fac. de Zootecnia e Engenharia de Alimentos, Av. Duque de Caxias Norte, no 225, CEP 13630-000 Pirassununga, SP. E-mail: amauryvalinote@yahoo.com.br, jocamano@usp.br, prleme@usp.br, sauloluz@usp.br, jcunha@usp.br

\begin{abstract}
Resumo - O objetivo deste trabalho foi avaliar a degradabilidade, a fermentação e a cinética ruminal de dietas com caroço de algodão ou sal de cálcio de ácidos graxos, como fontes de gordura, acrescidos de monensina sódica, e verificar o efeito da última em dietas com caroço de algodão. Quatro novilhos Nelore, canulados no rúmen, foram submetidos a um experimento em delineamento quadrado latino $4 \times 4$. Os tratamentos consistiram de três dietas com monensina (sal de cálcio graxo, caroço de algodão e controle) e uma dieta com caroço de algodão sem monensina. Os períodos de incubação foram de 0 , 3, 6, 12, 24, 48, 72 e 96 horas, e o líquido ruminal foi colhido nos horários 0, 1,5, 2, 3, 4, 6, 8, 12 e 24 horas depois da alimentação. As dietas com caroço de algodão apresentaram maior degradabilidade da fibra em detergente neutro e maior teor de proteína bruta. A dieta com caroço de algodão e monensina apresentou maior taxa de passagem líquida e turnover ruminal. Não houve diferença entre as dietas quanto ao $\mathrm{pH}$, amônia ruminal e ácidos graxos voláteis. As fontes de gordura, sal de cálcio de ácidos graxos e caroço de algodão não apresentaram efeito deletério no rúmen. A utilização de monensina afeta a degradabilidade, a cinética e a fermentação ruminal, quando se utiliza caroço de algodão na dieta.
\end{abstract}

Termos para indexação: caroço de algodão, rúmen, degradação ruminal, parâmetros ruminais, sais de cálcio de ácidos graxos.

\section{Lipid and sodic monensin sources in the rumen fermentation, kinetics and degradability}

\begin{abstract}
The objective of this work was to evaluate degradability in the rumen, fermentation and kinetics of diets with whole cottonseed or calcium salt of fatty acid, used as fat sources, with sodium monensin, as well as to verify the monensin effect on diet with cottonseed. Treatments consisted of three diets with monensin (control, calcium salt of fatty acid and cottonseed) and one diet with cottonseed without monensin. The incubation periods were 0, 3, 6, 12, 24, 48, 72 and 96 hours, and the ruminal liquid was sampled 0, 1.5, 2, 3, 4, 6, 8, 12 and 24 hours after feeding. Diets with cottonseed showed the highest degradability of the neutral detergent fiber and crude protein. Diets containing cottonseed with monensina showed the highest liquid passage and turnover. There were no differences, between the diets, related to ruminal $\mathrm{pH}$, ammonia and volatile fatty acids. The fat sources, calcium salt of fatty acid and whole cottonseed, showed no deleterious effects of the fat on the rumen environment. The inclusion of monensin affects the degradability, rumen kinetics and fermentation, when high concentrate diets with fat as whole cottonseed is fed.
\end{abstract}

Index terms: cottonseed, rumen, degradation in the rumen, ruminal parameters, calcium salt of fatty acids.

\section{Introdução}

A seleção de bovinos de corte com maior velocidade de ganho de peso e acabamento aumenta as exigências nutricionais, sobretudo de energia. Para suprir as exigências de energia digestível, é comum se adicionar maiores quantidades de carboidratos solúveis, prática que pode comprometer a ingestão de fibra e prejudicar o funcionamento ruminal, além de promover uma redução acentuada no pH ruminal, causando distúrbios metabólicos. A utilização de lipídios nas dietas para ruminantes é uma alternativa para evitar esses efeitos, pois promove digestão e absorção pós-ruminal, aumentando assim a densidade energética da dieta (Palmquist et al., 1993).

Dietas de ruminantes geralmente possuem $4 \%$ de lipídios. Teores maiores que 7\% da matéria seca podem ser prejudiciais à degradação do alimento, principalmente se houver elevada proporção de ácidos graxos 
insaturados que, além de serem tóxicos aos microrganismos ruminais, aderem à partícula do alimento e criam uma barreira física à ação de microrganismos e de enzimas microbianas (Sullivan et al., 2004).

Ao atingir o rúmen, os lipídios, na forma esterificada, sofrem lise por enzimas microbianas (lipólise), e os ácidos graxos insaturados sofrem posterior hidrogenação, processo denominado bio-hidrogenação, cujo principal objetivo é o de reduzir o efeito deletério da gordura no rúmen (Sullivan et al., 2004). Os principais responsáveis por esse mecanismo são as bactérias Butyrivibrio fibrisolvens, Anaerovibrio lipolytica e Propionibacter (Bauman et al., 1999; Pariza et al., 2001).

Para evitar o efeito negativo da gordura no ambiente ruminal e, conseqüentemente, na degradabilidade da fibra, várias fontes de lipídios e seus efeitos na cinética ruminal têm sido estudados. Algumas fontes, amplamente utilizadas no Brasil, são as sementes oleaginosas como o caroço de algodão. Elas possuem liberação lenta de gordura, o que ocasiona pequeno efeito na função ruminal (Sullivan et al., 2004). Outras fontes são as gorduras protegidas, sendo os sais de cálcio de ácidos graxos fontes lipídicas comerciais praticamente inertes à ação microbiana no ambiente ruminal (Grummer, 1995).

Antibióticos ionóforos têm sido muito utilizados nas dietas de bovinos confinados, com a finalidade de manipular a fermentação pela seleção de microrganismos, de forma a melhorar a eficiência alimentar, ao aumentar a concentração de ácido propiônico, reduzir as concentrações de amônia, hidrogênio e ácido lático e manter o pH com valores mais elevados (Lana \& Russel, 2000). Chalupa et al. (1986) citam que ionóforos e gorduras podem apresentar interações, pelo fato de possuírem efeitos análogos no rúmen.

Mesmo atuando nas bactérias gram-positivas, algumas bactérias gram-negativas podem mudar suas propriedades metabólicas em presença de ionóforos (Van Nevel \& Demeyer, 1995). A lipólise ruminal é realizada por bactérias gram-negativas, sendo que a utilização de monensina, em dietas com adição de gordura, poderia reduzir a bio-hidrogenação.

O objetivo deste trabalho foi avaliar a degradabilidade, a fermentação e a cinética ruminal de dietas com caroço de algodão ou sal de cálcio de ácidos graxos como fontes de gordura, acrescidos de monensina sódica, e verificar o efeito da monensina sódica em dietas com caroço de algodão.

\section{Material e Métodos}

O estudo foi conduzido no Campus Administrativo de Pirassununga, na Faculdade de Zootecnia e Engenharia de Alimentos da Universidade de São Paulo, no período de março a julho de 2002.

Foram utilizados quatro novilhos da raça Nelore, com cânulas ruminais e peso médio de $502 \pm 32 \mathrm{~kg}$, que permaneceram em baias com piso cimentado, em contenção feita por cabresto e correntes, com bebedouros automáticos e cochos de alvenaria.

Os animais foram arraçoados com dietas de canade-açúcar picada (volumoso) e quatro concentrados: dieta controle com monensina (CTRL), dieta com sal de cálcio de ácidos graxos com monensina (SC), dieta com caroço de algodão com monensina (CA) e dieta com caroço de algodão sem monensina (CASM) (Tabela 1). A relação volumoso:concentrado foi 81:19, em porcentagem de matéria seca. No cálculo das exigências nutricionais, foi utilizado o Cornell Net Carbohydrate and Protein System, para animais com ganho de peso médio de 1,27 kg dia-1.

Tabela 1. Composição porcentual e química das dietas, em base $\operatorname{seca}^{(1)}$.

\begin{tabular}{|c|c|c|c|c|}
\hline \multirow[t]{2}{*}{ Ingrediente } & \multicolumn{4}{|c|}{ Tratamento $^{(2)}$} \\
\hline & CTRL & $\mathrm{SC}$ & $\mathrm{CA}$ & $\overline{\text { CASM }}$ \\
\hline Milho grão & 29,362 & 26,538 & 21,178 & 21,178 \\
\hline Polpa de citrus & 37,188 & 33,612 & 26,822 & 26,822 \\
\hline Farelo de soja 49\% & 12,500 & 14,000 & 9,000 & 9,000 \\
\hline Uréia & 0,950 & 0,850 & 0,500 & 0,500 \\
\hline Sal mineral & 1,000 & 1,000 & 1,000 & 1,000 \\
\hline Calcário & - & - & 1,500 & 1,500 \\
\hline Caroço de algodão & - & - & 21,000 & 21,000 \\
\hline Sal de cálcio de ácidos graxos ${ }^{(3)}$ & - & 5,000 & - & - \\
\hline Rumensin ${ }^{(4)}$ & 0,027 & 0,027 & 0,027 & - \\
\hline Cana-de-açúcar & 19,000 & 19,000 & 19,000 & 19,000 \\
\hline Total & 100,0001 & 100,000 & 100,000 & 100,000 \\
\hline \multicolumn{5}{|l|}{ Nutriente } \\
\hline Matéria seca & 63,25 & 63,46 & 63,56 & 63,54 \\
\hline Proteína bruta & 16,42 & 17,02 & 15,65 & 14,81 \\
\hline Extrato etéreo & 4,93 & 9,58 & 9,12 & 7,79 \\
\hline Fibra em detergente neutro & 22,69 & 22,00 & 30,81 & 28,52 \\
\hline Fibra em detergente ácido & 22,18 & 19,65 & 25,42 & 20,85 \\
\hline Cálcio & 0,89 & 1,32 & 1,22 & 1,22 \\
\hline Fósforo & 0,30 & 0,30 & 0,32 & 0,32 \\
\hline Potássio & 0,91 & 0,91 & 1,00 & 1,00 \\
\hline
\end{tabular}

${ }^{(1)}$ Composição química avaliada por análise bromatológica (Association of Official Analytical Chemists, 1999). (2)CTRL: tratamento controle, com monensina; SC: tratamento com sal de cálcio de ácido graxo e monensina; CA: tratamento com caroço de algodão e monensina; CASM: tratamento com caroço de algodão sem monensina. (3)LAC 100. ${ }^{(4)}$ Rumensin: 10\% de monensina sódica. 
O arraçoamento foi fornecido duas vezes ao dia, em quantidade de matéria seca (MS) equivalente a $2 \%$ do peso vivo, durante o período de 14 dias de adaptação. As sobras foram retiradas e pesadas, diariamente, antes da primeira alimentação. No período de ensaio, de degradabilidade e de colheita de líquido ruminal, o alimento fornecido correspondeu a $90 \%$ da ingestão média dos animais, de forma que não houvesse sobras, para evitar que eles selecionassem a dieta.

As amostras de líquido ruminal foram colhidas por meio de bomba a vácuo e captadas em kitassato, na quantidade aproximada de $100 \mathrm{~mL}$. As colheitas foram realizadas 0 , 2, 4, 6 e 8 horas depois da alimentação, para análises de ácidos graxos voláteis (AGV) e nitrogênio amoniacal ( $\left(\mathrm{N}^{-} \mathrm{NH}_{3}\right)$, e 0, 1,5, 3, 6, 12 e 24 horas para análise do marcador de fase líquida na mensuração de volume ruminal, taxa de passagem líquida e fluxo líquido por quilograma de MS consumida por hora (turnover).

A fermentação ruminal foi mensurada pela análise de $\mathrm{pH}$, concentração de $\mathrm{N}-\mathrm{NH}_{3}$ e AGV. A determinação do $\mathrm{pH}$ do líquido ruminal foi feita logo depois da colheita, em peagômetro de mesa, calibrado com soluções tampão de pH 4 e pH 7. Uma parcela de $2 \mathrm{~mL}$ do fluído colhido foi adicionada em frasco de vidro com 0,4 mL de ácido fórmico e, então, congelada a $-20^{\circ} \mathrm{C}$, para posterior análise qualitativa e quantitativa de ácidos graxos voláteis, segundo método adaptado de Erwin et al. (1961), utilizando-se cromatografia gasosa.

Uma alíquota de $2 \mathrm{~mL}$ de fluído ruminal foi adicionada, em recipiente de vidro, a $1 \mathrm{~mL}$ de ácido sulfúrico $1 \mathrm{~N}$. As amostras foram congeladas e armazenadas, para posterior determinação da amônia ruminal, realizada por colorimetria pelo método de Weatherburn (1967).

A cinética ruminal foi avaliada mediante determinação do volume ruminal, fluxo líquido por hora e fluxo líquido por quilograma de MS consumida por hora (turnover). Foi aplicada a técnica de Hyden (1959), utilizando-se como marcador de fase líquida o polietilenoglicol (Carbowax F-4.000, marca Synth), com peso molecular 4.000 (PEG-4.000F). Foram diluídos $300 \mathrm{~g}$ do marcador em $1 \mathrm{~L}$ de água destilada, e essa solução foi despejada no rúmen uma hora antes da primeira alimentação, através da cânula ruminal, para que na primeira colheita houvesse maior homogeneidade do marcador no conteúdo do rúmen.

A degradabilidade ruminal in situ foi realizada segundo a técnica de Orskov \& McDonald (1979), utilizando-se sacos de náilon de $7 \mathrm{x} 14 \mathrm{~cm}$ e poros de $50 \mu \mathrm{m}$. O período de incubação foi de $0,3,6,12,24,48,72$ e 96 horas depois da alimentação dos animais, no décimo sétimo dia do período experimental. Para análise do tempo zero, ou seja, antes da alimentação, os sacos de náilon foram mergulhados em água aquecida a $39^{\circ} \mathrm{C}$ por $15 \mathrm{~min}$. Para cada período de incubação, foram utilizados três sacos de náilon, num total de 24 sacos por animal, por período experimental.

O porcentual de degradabilidade de matéria seca foi calculado pela fórmula:

$\mathrm{DMS} \%=\left(1-\frac{\mathrm{SPI}-\mathrm{SV}}{\mathrm{SAI}-\mathrm{SV}}\right) \times 100$

em que DMS\% é o porcentual de degradabilidade da MS; SPI é o peso do saco depois da incubação ruminal; SAI é o peso do saco antes da incubação ruminal; e SV é o peso do saco vazio.

O cálculo do porcentual de degradabilidade de cada nutriente foi efetuado por meio da fórmula acima, e as diferenças (SPI - SV) e (SAI - SV) foram multiplicadas pelas respectivas porcentagens de cada nutriente.

Os dados de degradabilidade foram ajustados pelo modelo de Orskov e McDonald (1979), conforme a equação: $\mathrm{p}=\mathrm{a}+\mathrm{b}$ (01 - $\left.\mathrm{e}^{-\mathrm{ct}}\right)$, em que p é a quantidade degradada no tempo t; a é a intersecção da curva no tempo zero, a fração rapidamente solúvel; b é a fração potencialmente degradável, a fração degradada no tempo; c é a taxa horária de degradação da fração potencialmente degradável; e é o log natural de -ct; e t é o tempo.

As constantes a, b e c foram utilizadas para cálculos da degradabilidade potencial e degradabilidade efetiva, conforme equação de Orskov et al. (1980):

$\mathrm{p}=\mathrm{a}+\frac{\mathrm{bc}}{\mathrm{c}+\mathrm{k}}$, em que $\mathrm{p}$ representa a taxa de degradabilidade efetiva; a é a intersecção da curva no tempo zero, a fração rapidamente solúvel; b é a fração potencialmente degradável, a fração degradada no tempo; c é a taxa horária de degradação da fração potencialmente degradável; e k é a taxa de saída do rúmen por hora.

Foram consideradas as taxas de passagem de 2, 5 e $8 \% \mathrm{~h}^{-1}$, as quais podem ser atribuídas aos níveis de ingestão alimentar baixo, médio e alto.

A degradabilidade potencial foi obtida pela soma das frações a e b.

Foram realizadas as análises de matéria seca, proteína bruta (PB), fibra em detergente ácido (FDA), fibra em detergente neutro (FDN), extrato etéreo do alimento e 
dos resíduos da degradabilidade, segundo metodologia da Association of Official Analytical Chemists (1999).

O delineamento experimental utilizado foi o quadrado latino (4x4). Os efeitos dos tratamentos e da interação de tempo $\mathrm{x}$ tratamento foram avaliados, utilizando-se o procedimento Mixed do SAS (1985). Foram avaliados os seguintes contrastes: controle $\mathrm{x}$ tratamentos com lipídios, sais de cálcio de ácidos graxos x tratamentos com caroço de algodão, tratamento com caroço de algodão e monensina $\mathrm{x}$ tratamento com caroço de algodão sem monensina. As características avaliadas, em diferentes tempos, foram analisadas como medidas repetidas. Foram considerados efeitos até 5\% de probabilidade.

\section{Resultados e Discussão}

Os dados das frações a, b e c, assim como da degradabilidade potencial e efetiva da matéria seca, fibra em detergente neutro e fibra em detergente ácido, da cana-de-açúcar, estão representados na Tabela 2. Para a fibra em detergente neutro, o fornecimento de lipídio provocou redução na fração potencialmente degradável (constante b) do volumoso e na degradabilidade potencial e efetiva, quando foram utilizadas as taxas de passagem 0,02, 0,05 e 0,08. Com isso, verificou-se que as fontes de lipídios afetaram, negativamente, a degradação dos carboidratos. Em contraste, Ruy et al. (1996) afirmam que a utilização de caroço de algodão parece favorecer a degradação da fibra, no entanto eles utilizaram níveis menores de concentrado e de caroço de algodão, em relação ao presente estudo, o que certamente interfere na degradação ruminal.

Com relação às fontes de gordura, as frações potencialmente degradáveis, taxa de degradação (constantes b e c) e degradação potencial da FDN da cana-de-açúcar, foram maiores quando os animais foram alimentados com caroço de algodão, em relação ao sal de cálcio de ácidos graxos, assim como a degradabilidade efetiva, considerando-se as três taxas de passagem. A degradação da proteína do caroço de algodão é, possivelmente,

Tabela 2. Frações solúvel (a) e potencialmente degradável (b), taxa de degradação (c), degradabilidade potencial (Dp) e degradabilidade efetiva (De), para taxas de passagem iguais a 0,02, 0,05 e 0,08, de dietas com diferentes fontes de gordura, com monensina ou sem monensina, das variáveis matéria seca, fibra em detergente neutro e fibra em detergente ácido da cana-de-açúcar.

\begin{tabular}{|c|c|c|c|c|c|c|c|c|}
\hline \multirow{2}{*}{$\begin{array}{l}\text { Fração das } \\
\text { dietas }\end{array}$} & \multicolumn{5}{|c|}{ Tratamento $^{(1)}$} & \multicolumn{3}{|c|}{ Contraste $^{(2)}$} \\
\hline & CTRL & $\mathrm{SC}$ & CA & CASM & Erro-padrão & CTRLxLipídio & $\mathrm{SCxCaA}$ & CAxCASM \\
\hline & \multicolumn{8}{|c|}{ Matéria seca } \\
\hline $\mathrm{a}$ & 44,47 & 43,50 & 43,59 & 43,88 & 0,6833 & 0,9712 & 0,3153 & 0,9354 \\
\hline $\mathrm{b}$ & 27,56 & 24,58 & 25,73 & 24,33 & 1,6696 & 0,5092 & 0,3679 & 0,6998 \\
\hline $\mathrm{c}$ & 0,060 & 0,050 & 0,065 & 0,055 & 0,0144 & 0,8695 & 0,9074 & 0,5518 \\
\hline Dp & 72,03 & 68,09 & 69,32 & 68,21 & 1,6666 & 0,4996 & 0,2091 & 0,6670 \\
\hline De $(0,02)$ & 64,91 & 60,51 & 62,51 & 60,71 & 2,1629 & 0,4914 & 0,2709 & 0,5591 \\
\hline De $(0,05)$ & 59,30 & 55,42 & 57,48 & 55,79 & 2,1868 & 0,5754 & 0,3617 & 0,5584 \\
\hline \multirow[t]{2}{*}{ De $(0,08)$} & 56,13 & 52,72 & 54,67 & 53,17 & 2,0023 & 0,6141 & 0,3972 & 0,5504 \\
\hline & \multicolumn{8}{|c|}{ Fibra em detergente neutro } \\
\hline $\mathrm{a}$ & 7,29 & 8,11 & 8,68 & 6,74 & 0,6275 & 0,1503 & 0,2323 & 0,5720 \\
\hline $\mathrm{b}$ & 53,70 & 44,79 & 36,26 & 55,50 & 2,8450 & $0,0238^{*}$ & $0,0124^{*}$ & 0,0956 \\
\hline $\mathrm{c}$ & 0,292 & 0,052 & 0,060 & 0,257 & 0,0469 & 0,1049 & $0,0133^{*}$ & 0,9271 \\
\hline Dp & 60,99 & 52,89 & 44,94 & 62,25 & 3,0947 & $0,0479^{*}$ & $0,0230^{*}$ & 0,1344 \\
\hline De $(0,02)$ & 57,07 & 40,31 & 34,11 & 57,15 & 1,4810 & $0,0003^{*}$ & $<0,0001^{*}$ & $0,0268^{*}$ \\
\hline De $(0,05)$ & 52,25 & 30,83 & 26,55 & 51,25 & 1,3064 & $<0,0001^{*}$ & $<0,0001^{*}$ & 0,0623 \\
\hline \multirow[t]{2}{*}{ De $(0,08)$} & 48,34 & 25,68 & 22,54 & 46,74 & 1,5721 & $0,0003^{*}$ & $<0,0001^{*}$ & 0,2332 \\
\hline & \multicolumn{8}{|c|}{ Fibra em detergente ácido } \\
\hline $\mathrm{a}$ & 6,03 & 5,78 & 4,51 & 5,70 & 0,8369 & 0,6918 & 0,2327 & 0,1492 \\
\hline $\mathrm{b}$ & 49,98 & 50,34 & 46,23 & 41,40 & 4,1796 & 0,2309 & 0,7847 & 0,5705 \\
\hline $\mathrm{c}$ & 0,057 & 0,077 & 0,120 & 0,092 & 0,0194 & 0,7858 & 0,1910 & 0,2366 \\
\hline $\mathrm{Dp}$ & 56,01 & 56,13 & 50,75 & 47,11 & 4,4077 & 0,2652 & 0,6925 & 0,4814 \\
\hline De $(0,02)$ & 41,53 & 43,80 & 43,18 & 38,33 & 2,2131 & 0,0905 & 0,4400 & 0,8265 \\
\hline De $(0,05)$ & 31,16 & 34,33 & 35,83 & 30,86 & 1,7525 & 0,1337 & 0,0702 & 0,4936 \\
\hline De $(0,08)$ & 25,59 & 28,85 & 30,95 & 26,32 & 1,6769 & 0,2826 & 0,0667 & 0,3825 \\
\hline
\end{tabular}

${ }^{(1) C T R L: ~ t r a t a m e n t o ~ c o n t r o l e, ~ c o m ~ m o n e n s i n a ; ~ S C: ~ t r a t a m e n t o ~ c o m ~ s a l ~ d e ~ c a ́ l c i o ~ d e ~ a ́ c i d o ~ g r a x o ~ e ~ m o n e n s i n a ; ~ C A: ~ t r a t a m e n t o ~ c o m ~ c a r o c ̧ o ~ d e ~}$ algodão e monensina; CASM: tratamento com caroço de algodão sem monensina. ${ }^{(2)}$ CTRLxLipídio: tratamento controle x tratamentos com adição de lipídios; SCxCaA: tratamento com sais de cálcio de ácidos graxos x tratamentos com caroço de algodão; CAxCASM: tratamento com caroço de algodão e monensina x tratamento com caroço de algodão sem monensina. *Significativo a 5\% de probabilidade pelo teste $\mathrm{F}$. 
mais lenta que a do farelo de soja; assim, pode-se ter melhor aproveitamento de nitrogênio pelos microrganismos ruminais, o que favorece a atuação deles na degradação da fibra.

Houve aumento em 51,27\% na degradabilidade efetiva com $2 \%$ de taxa de passagem, quando o tratamento com caroço de algodão não tinha monensina, e pode-se verificar tendência de aumento, quando a taxa de passagem foi para 5\%, para o tratamento CASM. É possível que tenha ocorrido efeito associativo entre a gordura e a monensina, ambos tóxicos para bactérias gram-positivas, principais responsáveis pela degradação da fibra.

Os valores de degradabilidade das dietas estão representados na Tabela 3.

Para a degradabilidade da proteína bruta das dietas, houve maiores valores da fração a e da degradabilidade efetiva a $8 \%$ de taxa de passagem, para as dietas com adição de lipídio. Pode ser que, depois do rompimento ou eliminação da casca envoltória da semente do caroço de algodão, haja maior solubilidade tanto da gordura quanto da proteína, fato ocorrido no processamento das amostras para preenchimento dos sacos de degradabilidade, o que explica o fato de as dietas com caroço terem apresentado valores da fração solúvel, na
MS, inferiores à da dieta SC. Da mesma forma, esse fator pode ter contribuído para redução da fração a das dietas com gordura, em relação à dieta controle.

Houve maior taxa de degradação da proteína para as dietas com caroço de algodão, em relação à dieta com sais de cálcio de ácidos graxos, possivelmente pela maior solubilidade da PB do caroço de algodão na amostra moída.

Comparando-se as dietas com caroço de algodão, o tratamento com monensina apresentou maior valor para a fração solúvel e menor valor para a fração potencialmente degradável, como também ocorreu na degradabilidade da MS. No entanto, a taxa de degradação foi $65 \%$ maior para esta dieta, o que resultou em maior degradabilidade efetiva para todas as taxas de passagem utilizadas.

Ao contrário do observado neste estudo, a adição de lipídio, na forma de sais de cálcio de ácidos graxos, promoveu leve aumento na digestão ruminal da MS e da fibra, quando comparada à ração controle, em estudo realizado por Jenkins \& Palmquist (1984), possivelmente, em razão do fornecimento de dietas com maior proporção de volumoso. Zinn \& Borques (1993) verificaram menor digestão ruminal da matéria orgânica, com uma tendência de diminuição da digestão ruminal da FDA e nitrogênio,

Tabela 3. Frações solúvel (a) e potencialmente degradável (b), taxa de degradação (c), degradabilidade potencial (Dp) e degradabilidade efetiva (De), para taxas de passagem iguais a 0,02, 0,05 e 0,08, de dietas com diferentes fontes de gordura com monensina ou sem monensina, das variáveis matéria seca e proteína bruta das dietas.

\begin{tabular}{|c|c|c|c|c|c|c|c|c|}
\hline \multirow{2}{*}{$\begin{array}{l}\text { Frações das } \\
\text { dietas }\end{array}$} & \multicolumn{5}{|c|}{ Tratamento $^{(1)}$} & \multicolumn{3}{|c|}{ Contraste $^{(2)}$} \\
\hline & CTRL & $\mathrm{SC}$ & $\mathrm{CA}$ & CASM & Erro-padrão & CTRLxLipídio & $\mathrm{SCxCaA}$ & CAxCASM \\
\hline & & & & & Matéria seca & & & \\
\hline $\mathrm{a}$ & 36,64 & 33,24 & 35,64 & 35,24 & 0,8494 & 0,9335 & $0,0322^{*}$ & $0,0397^{*}$ \\
\hline b & 53,12 & 57,37 & 49,39 & 53,73 & 1,7181 & 0,7988 & 0,8844 & $0,0072^{*}$ \\
\hline $\mathrm{c}$ & 0,080 & 0,072 & 0,085 & 0,078 & 0,0083 & 0,8748 & 0,9112 & 0,3529 \\
\hline $\mathrm{Dp}$ & 89,76 & 90,61 & 85,03 & 88,97 & 1,2305 & 0,6871 & 0,1731 & $0,0084^{*}$ \\
\hline De $(0,02)$ & 78,95 & 77,86 & 75,35 & 77,68 & 1,2682 & 0,7650 & 0,0544 & 0,0688 \\
\hline $\operatorname{De}(0,05)$ & 69,11 & 66,94 & 66,40 & 67,59 & 1,5056 & 0,9210 & 0,1320 & 0,7982 \\
\hline \multirow[t]{2}{*}{ De $(0,08)$} & 63,00 & 60,22 & 60,77 & 61,40 & 1,5380 & 0,9621 & 0,1559 & 0,7702 \\
\hline & & & & & Proteína bruta & & & \\
\hline $\mathrm{a}$ & 37,15 & 28,29 & 41,41 & 40,87 & 1,1953 & $0,0082^{*}$ & 0,1622 & $0,0002^{*}$ \\
\hline $\mathrm{b}$ & 53,82 & 69,34 & 48,50 & 51,21 & 3,1015 & 0,1177 & 0,1944 & $0,0021^{*}$ \\
\hline $\mathrm{c}$ & 0,050 & 0,040 & 0,105 & 0,065 & 0,0045 & 0,9953 & $0,0219^{*}$ & $0,0003^{*}$ \\
\hline $\mathrm{Dp}$ & 90,97 & 97,63 & 89,91 & 92,09 & 2,8552 & 0,8036 & 0,3939 & 0,0708 \\
\hline De $(0,02)$ & 75,30 & 74,25 & 82,15 & 79,87 & 1,9054 & 0,2529 & 0,2369 & $0,0213^{*}$ \\
\hline De $(0,05)$ & 63,75 & 58,94 & 74,27 & 69,63 & 1,4547 & 0,0557 & 0,1601 & $0,0003^{*}$ \\
\hline De $(0,08)$ & 57,58 & 51,31 & 68,95 & 63,66 & 1,2396 & $0,0218^{*}$ & 0,1432 & $<0,0001^{*}$ \\
\hline
\end{tabular}

(1)CTRL: tratamento controle, com monensina; SC: tratamento com sal de cálcio de ácido graxo e monensina; CA: tratamento com caroço de algodão e monensina; CASM: tratamento com caroço de algodão, sem monensina. (2)CTRLxLipídio: tratamento controle x tratamentos com adição de lipídios; SCxCaA: tratamento com sais de cálcio de ácidos graxos x tratamentos com caroço de algodão; CAxCASM: tratamento com caroço de algodão e monensina x tratamento com caroço de algodão, sem monensina. *Significativo a 5\% de probabilidade pelo teste F. 
pela adição de monensina em dietas com gordura, possivelmente, por se tratar de gordura animal.

A monensina parece atuar negativamente na proliferação de microrganismos lipolíticos (Van Nevel \& Demeyer, 1995), o que pode causar diminuição da biohidrogenação ruminal. Por conseguinte, há aumento na quantidade de ácidos graxos insaturados no rúmen, o que pode prejudicar a degradação ruminal, principalmente em dietas com alto teor de grãos, assim como ocorreu neste estudo, em que a degradabilidade potencial da matéria seca foi menor para dietas com caroço de algodão e monensina. Por se tratar de um alimento com baixa liberação lipídica, o efeito da monensina, na dieta CA, não foi tão efetivo quanto poderia ser em uma dieta com adição de óleo simplesmente.

$\mathrm{O}$ volume ruminal, taxa de passagem líquida e turnover (Tabela 4) não foram diferentes entre os tratamentos com ou sem lipídios e concordam com os resultados de Clary et al. (1993), que observaram esse mesmo resultado, quando foi adicionada gordura, lasalocida ou monensina à dieta com gordura. Os valores dessas variáveis, nos tratamentos com caroço de algodão, foram superiores aos encontrados por Ruy et al. (1996), que utilizaram as proporções de 0, 6,6 e 15\% de caroço de algodão na dieta.

Houve aumento do turnover do tratamento CA comparado ao CASM; a única explicação encontrada para isso foi a de que a dieta com monensina apresentou degradabilidade efetiva superior à dieta sem monensina. Essa maior degradação implica em maior velocidade de renovação do material no rúmen, significando um turnover maior.

Houve aumento do pH ruminal (Tabela 4) pela adição de gordura, que diverge dos resultados relatados por Ruy et al. (1996) e Chalupa et al. (1986), que não observaram modificações no pH com a adição de lipídios. Palmquist et al. (1993) observaram redução do pH com adição de gordura no horário anterior à alimentação, e aumento nos horários posteriores. Valores superiores de $\mathrm{pH}$, para animais que receberam lipídios na dieta, são esperados, em comparação aos de animais com dietas controle, pois por serem tóxicos a bactérias gram-positivas, os ácidos graxos de cadeia longa inibem a proliferação de bactérias produtoras de ácido lático.

A monensina não interferiu no $\mathrm{pH}$ do tratamento que utilizou caroço de algodão, o que concorda com os resultados encontrados por Clary et al. (1993) e Zinn \& Borques (1993).

Não houve interação tempo x tratamento nas concentrações de nitrogênio amoniacal, ácido acético, propiônico e butírico e na concentração total de ácidos graxos voláteis, assim como não houve efeito para nenhum contraste testado (Figura 1). Esses resultados estão de acordo com os obtidos por Clary et al. (1993), que não observaram diferenças entre dietas com adição de gordura, com monensina ou sem monensina.

Tabela 4. Parâmetros de fermentação ruminal e cinética líquida ruminal, de novilhos Nelore alimentados com dietas com diferentes fontes de gordura, com monensina ou sem monensina.

\begin{tabular}{|c|c|c|c|c|c|c|c|c|}
\hline \multirow[t]{2}{*}{ Parâmetro } & \multicolumn{5}{|c|}{ Tratamento $^{(1)}$} & \multicolumn{3}{|c|}{ Contraste $^{(2)}$} \\
\hline & CTRL & $\mathrm{SC}$ & $\mathrm{CA}$ & CASM & Erro-padrão & $\overline{\text { CTRLxLipídio }}$ & $\mathrm{SCxCaA}$ & CAxCASM \\
\hline$\overline{\mathrm{pH}}$ & 6,33 & 6,32 & 6,41 & 6,49 & 0,041 & $0,0057^{*}$ & 0,5700 & 0,1205 \\
\hline Ácido acético $(\mathrm{mM})$ & 60,53 & 62,63 & 65,39 & 60,89 & 4,122 & 0,6820 & 0,4933 & 0,6375 \\
\hline Ácido propiônico (mM) & 25,76 & 21,27 & 21,82 & 26,01 & 3,260 & 0,4183 & 0,2949 & 0,9062 \\
\hline Ácido butírico $(\mathrm{mM})$ & 13,71 & 16,10 & 12,79 & 13,09 & 1,189 & 0,4230 & 0,6145 & 0,0536 \\
\hline Ácido acético:ácido propiônico & 3,14 & 3,58 & 3,51 & 3,06 & 0,279 & 0,2840 & 0,2394 & 0,8740 \\
\hline Total AGV (mM) & 76,18 & 77,81 & 75,64 & 74,77 & 5,364 & 0,7761 & 0,9344 & 0,7754 \\
\hline Nitrogênio amoniacal $\left(\mathrm{mg} \mathrm{dL}^{-1}\right)$ & 16,55 & 16,83 & 13,89 & 15,45 & 1,190 & 0,8254 & 0,4187 & 0,0854 \\
\hline Volume ruminal (L) & 40,33 & 37,86 & 35,32 & 41,58 & 4,665 & 0,5136 & 0,5378 & 0,7135 \\
\hline Taxa de passagem líquida $\left(\mathrm{L} \mathrm{h}^{-1}\right)$ & 6,95 & 6,69 & 10,49 & 8,90 & 1,299 & 0,5895 & 0,3429 & 0,0837 \\
\hline $\begin{array}{l}\text { Fluxo líquido por kg de MS } \\
\text { consumida por hora (L) }\end{array}$ & 1,67 & 1,60 & 3,27 & 3,13 & 0,417 & 0,9260 & 0,1858 & 光,0305 \\
\hline
\end{tabular}

(1)CTRL: tratamento controle, com monensina; SC: tratamento com sal de cálcio de ácido graxo e monensina; CA: tratamento com caroço de algodão e monensina; CASM: tratamento com caroço de algodão, sem monensina. ${ }^{(2) C T R L x L i p i ́ d i o: ~ t r a t a m e n t o ~ c o n t r o l e ~ x ~ t r a t a m e n t o s ~ c o m ~}$ adição de lipídios; SCxCaA: tratamento com sais de cálcio de ácidos graxos x tratamentos com caroço de algodão; CAxCASM: tratamento com caroço de algodão e monensina x tratamento com caroço de algodão, sem monensina. *Significativo a 5\% de probabilidade pelo teste F. 
Em contrapartida, Zinn \& Borques (1993) e Fellner et al. (1997) verificaram aumento na concentração de ácido propiônico e redução na concentração de ácido acético, com a adição monensina em dietas com gordura.

Jenkins et al. (2003), ao avaliar a utilização de óleo de soja, monensina ou ambos os aditivos em fermentadores in vitro, sobre a produção de ácidos graxos trans, observaram que a adição de gordura, sozinha ou com ionóforo, diminuiu a concentração de propionato, enquanto as concentrações de acetato, butirato, ácidos graxos totais, proporção de acetato:propionato e os valores de $\mathrm{pH}$ não foram alterados.

Assim como neste experimento, Palmquist et al. (1993) não encontraram diferenças nas concentrações e proporções de $\mathrm{AGV}$, quando adicionaram gordura na forma de sal de cálcio de ácidos graxos à dieta.

A monensina, em presença de gordura do caroço de algodão, não apresentou efeito na fermentação ruminal. No entanto, com a adição de monensina, houve redução da degradação da MS e aumento da degradação da PB da dieta. Segundo Clary et al. (1993), um dos mecanismos que explica a diminuição do efeito da gordura e do ionóforo, na fermentação ruminal, é a solubilidade do ionóforo em lipídios. Tanto ácidos graxos insaturados quanto a monensina possuem efeito semelhante no ambiente ruminal, e este pode ser o motivo de não haver efeito associativo entre o aditivo e o alimento.

Provavelmente, a maior atuação do ionóforo em dietas com gordura seja na composição do ácido graxo de

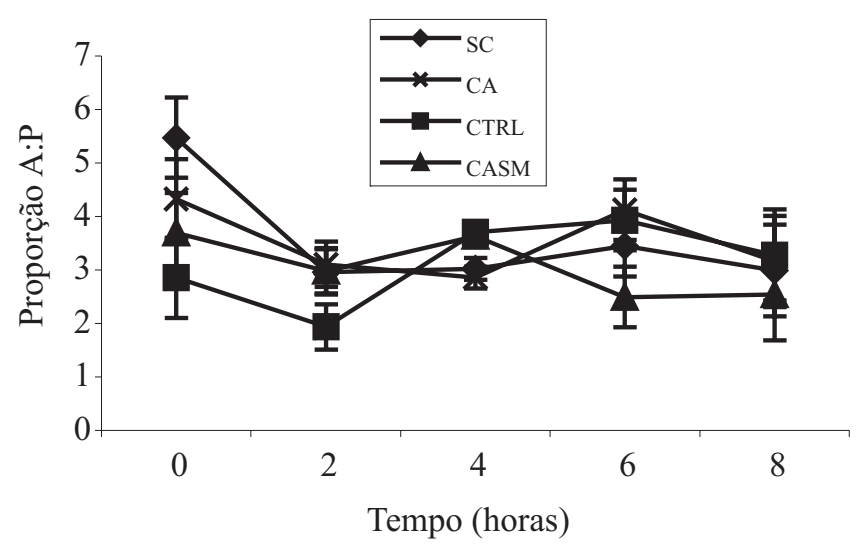

Figura 1. Curvas de proporção acético:propiônico (A:P) no rúmen de bovinos Nelore, em função do tempo, depois da alimentação com dietas com sais de cálcio de ácidos graxos e monensina (SC), caroço de algodão com monensina (CA), controle com monensina (CTRL) e caroço de algodão sem monensina (CASM). cadeia longa no rúmen e, conseqüentemente, no duodeno. Foi relatado que alguns microrganismos gramnegativos mudam suas propriedades em presença de monensina, o que explica a redução da lipólise. De acordo com Fellner et al. (1997) e Jenkins et al. (2003), a monensina reduziu a taxa de bio-hidrogenação por inibição da lipólise. Esse efeito na microbiota pode ser responsável pela alteração na degradação da MS e PB, neste estudo.

\section{Conclusões}

1. O fornecimento de lipídio, na forma de sais de cálcio de ácidos graxos e caroço de algodão, influencia a degradabilidade da fibra em detergente neutro da canade-açúcar, em dietas com alto teor de concentrado.

2. A influência do caroço de algodão na degradação da dieta, assim como na cinética ruminal, deve-se mais à fibra efetiva e à proteína solúvel do que à gordura.

3. A utilização de monensina, em dietas com caroço de algodão, afeta a degradabilidade ruminal da matéria seca e da proteína bruta.

\section{Agradecimentos}

À Fundação de Amparo à Pesquisa do Estado de São Paulo.

\section{Referências}

ASSOCIATION OF OFFICIAL ANALYTICAL CHEMISTS AOAC. Official methods of analysis. 11.ed. Washington, DC, 1999. 1051p.

BAUMAN, D.E.; BAUMGARD, L.H.; CORL, B.A.; GRIINARI, J.M. Biosynthesis of conjugated linoleic acid in ruminants. Proceedings of the American Society of Animal Science, 1999. Disponível em: <www.asas.org/jas/symposia/proceedings/ 0937.pdf>. Acesso em: jan. 2005.

CHALUPA, W.; VECCHIARELLI, B.; ELSER, A.E.; KRONFELD, D.S.; SKLAN, D.; PALMQUIST, D.L. Ruminal fermentation in vivo as influenced by long-chain fatty acids. Journal of Dairy Science, v.69, p.1293-1301, 1986.

CLARY, E.M.; BRANDT JUNIOR, R.T.; HARMON, D.L.; NAGARAJA, T.G. Supplemental fat and ionophores in finishing diets: feedlot performance and ruminal digesta kinetics in steers. Journal of Animal Science, v.71, p.3115-3123, 1993.

ERWIN, E.S.; MARCO, G.J.; EMERY, E.M. Volatile fatty acid analyses of blood and rumen fluid by gas chromatography. Journal of Dairy Science, v.44, p.1768-1771, 1961.

FELLNER, V.; SAUER, F.D.; KRAMER, J.K.G. Effect of nigericin, monensin, and tetronasin on biohydrogenation in continuous flow- 
through ruminal fermenters. Journal of Dairy Science, v.80, p.921928, 1997.

GRUMMER, R.R. Ruminal inertness vs. digestibility of fat supplements: can there be harmony? In: CORNELL NUTRITION CONFERENCE FOR FEED MANUFACTURERS, 57., 1995, Ithaca. Proceedings. Ithaca: Ithaca Cornell University, 1995. p.13-24.

HYDEN, S.A. A turbidimetric method for the determination of higher polyethylene glycols in biological materials. Kungl LantbruksHögskolans Annales, v.22, p.139-145, 1956.

JENKINS, T.C.; FELLNER, V.; McGUFFEY, R.K. Monensin by fat interactions on trans fatty acids in cultures of mixed ruminal microorganisms grown in continuous fermentors fed corn or barley. Journal of Dairy Science, v.86, p.324-330, 2003.

JENKINS, T.C.; PALMQUIST, D.L. Effect of fatty acids or calcium soaps on rumen and total nutrient digestibility of dairy rations. Journal of Dairy Science, v.67, p.978-986, 1984.

LANA, R. de P.; RUSSELL, J.B. Efeitos da monensina sobre a fermentação e sensibilidade de bactérias ruminais de bovinos sob dietas ricas em volumoso ou concentrado. Revista Brasileira de Zootecnia, v.30, p.254-260, 2001.

ORSKOV, E.R.; HOVELL, F.D.; MOULD, F. Uso de la técnica de la bolsa de nylon para la evaluación de los alimentos. Producción Animal Tropical, v.5, p.213-233, 1980.

ORSKOV, E.R.; McDONALD, I. The estimation of protein degradability in the rumen from incubation measurements weighted according to rate of passage. Journal of Agricultural Science, v.92, p.499-503, 1979.
PALMQUIST, D.L.; WEISBJERG, M.R.; HVELPLUND, T. Ruminal, intestinal, and total digestibilities of nutrients in cows fed diets high in fat and undegradable protein. Journal of Dairy Science, v.76, p.1353-1364, 1993.

PARIZA, M.W.; PARK, Y.; COOK, M.E. The biologically active isomers of conjugated linoleic acid. Progress in Lipid Research, v.40, p.283-298, 2001.

RUY, D.C.; LUCCI, C. de S.; MELOTTI, L.; LIMA, M.L.M. Degradação da proteína e fibra do caroço de algodão integral (Gossypium hirsutum L.) no rúmen. Brazilian Journal of Veterinary Research and Animal Science, v.33, p.276-280, 1996.

SAS INSTITUTE (Cary, Estados Unidos). User's guide: statistics. $5^{\text {th }}$ ed. Cary, 1995. 958p.

SULLIVAN, H.M.; BERNARD, J.K.; AMOS, H.E.; JENKINS, T.C. Performance of lactating dairy cows fed whole cottonseed with elevated concentrations of free fatty acids in the oil. Journal of Dairy Science, v.87, p.665-671, 2004.

VAN NEVEL, C.; DEMEYER, D.I. Lipolysis and biohydrogenation of soybean oil in the rumen in vitro: inhibition by antimicrobials. Journal of Dairy Science, v.78, p.2797-2806, 1995.

WEATHERBURN, M.V. Phenol-hypochlorite reaction for determination of ammonia. Analytical Chemistry, v.39, p.971-974, 1967.

ZINN, R.A.; BORQUES, J.L. Influence of sodium bicarbonate and monensin on utilization of a fat-supplemented high-energy, growingfinishing diet by feedlot steers. Journal of Animal Science, v.71, p.18-25, 1993. 